\title{
Fracture Behavior and Delamination Toughening of Molybdenum in Charpy Impact Tests
}

\author{
K. BABINSKY, ${ }^{1,5}$ S. PRIMIG, ${ }^{1,2,6}$ W. KNABL, ${ }^{3,7}$ A. LORICH, ${ }^{3,8}$ \\ R. STICKLER, ${ }^{4,9}$ and H. CLEMENS ${ }^{1,10}$
}

\begin{abstract}
1.-Department of Physical Metallurgy and Materials Testing, Montanuniversität Leoben, FranzJosef Straße 18, 8700 Leoben, Austria. 2.-School of Materials Science and Engineering, UNSW Australia, Sydney, NSW 2052, Australia. 3.-Plansee SE, Metallwerk-Plansee-Straße 71, 6600 Reutte, Austria. 4.-University of Vienna, Vienna, Austria. 5.-e-mail: katharina.babinsky@unileoben.ac.at. 6.—e-mail: s.primig@unsw.edu.au. 7.—e-mail: wolfram.knabl@plansee.com. 8.—e-mail: alexander.lorich@plansee.com. 9.—e-mail: roland.stickler@univie.ac.at. 10.—e-mail: helmut.clemens@unileoben.ac.at
\end{abstract}

This study combines advanced characterization techniques with conventional Charpy impact tests to relate the mechanical properties to the microstructure of technically pure molybdenum, especially regarding its toughness. V-notched samples with different orientations were prepared from a rolled molybdenum plate in stress-relieved and recrystallized condition. The ductile-tobrittle transition-temperature was analyzed in terms of the delamination behavior influenced by the microstructure. A pronounced increase of toughness was found for specific oriented samples, which can be explained by macroscopic delamination. Elongated grains led to enhanced delamination in Charpy impact tests with variations for different orientations. In general, delamination occurs as a result of brittle fracture; however, an increase in toughness in the Charpy impact test can be provoked. This mechanism is called thin sheet toughening or delamination toughening. Electron backscatter diffraction measurements were performed to get a deeper knowledge about crack propagation and delamination behavior in the rolled plate. Recrystallization shifts the transition region to significantly higher temperatures, which is explained by the globular grain shape as well as grain boundary segregation. The occurrence of delamination is discussed, taking texture, grain shape and segregation effects into account.

\section{INTRODUCTION}

Molybdenum belongs to the group of refractory metals and has a high melting point, high temperature strength and good electrical and thermal conductivity. Due to these outstanding properties, it is used for several high-performance applications in electronics, coatings, high-temperature engineering, and lighting technology. Nevertheless, its fabrication and processing as well as its applicability as a high-performance material are limited because of a ductile-to-brittle transition-temperature (DBTT) around room temperature. ${ }^{1-3}$ With its body-centered cubic (bcc) structure, thermal activation is necessary to overcome the Peierls potential for plastic deformation, causing a pronounced transition from ductile to brittle. However, controlling grain size, grain shape, grain boundary character, alloying content, and stress state seem to be key approaches to influencing the DBTT of molybdenum. ${ }^{4-9}$ Nevertheless, recrystallization annealing of the as-deformed and stress-relieved condition of molybdenum leads to a significant increase of the DBTT and even more to intergranular embrittlement, which is believed to be caused by the larger grain size and segregation enrichments at the grain boundaries. ${ }^{4-6,10-13}$ Recent atom probe investigations revealed phosphor, nitrogen and oxygen impurities at the grain boundaries of technically pure molybdenum $^{14,15}$ of which especially segregated oxygen is assumed to promote intergranular failure. ${ }^{6,11,12}$ By adding small amounts of carbon and boron, the ductility of molybdenum can be improved. $^{4,11,16}$ 
However, molybdenum suffers from severe delamination, a typical splitting of grains boundaries, in the transition and upper shelf regions due to the anisotropic grain geometry which makes its processing challenging. In the past, different investigation methods have been applied to solve the problem of delamination. ${ }^{17,18}$ Quasi-static pull tests led to the assumption that linear arrangements of former micropores, which become flattened during hot-deformation, cause the delamination susceptibility of molybdenum. ${ }^{19}$ Cockeram ${ }^{4,20-23}$ tested the fracture toughness and mechanisms of wrought molybdenum and molybdenum alloys. He observed a pronounced dependency of the DBTT on the grain size and grain shape. An elongated, pancake-shaped grain structure leads to an anisotropy in fracture toughness. In the transition and upper shelf regions, splitting of grains boundaries occurs and generates a ductile laminate failure mode. This cracking of grain boundaries leaves ligaments which stretch and fail under a plane stress condition in a ductile manner. This thin sheet toughening, which is also known as delamination toughening, occurs to a differing extent depending on the specimen orientation in respect to the grain shape. ${ }^{4,20-27}$

In previous studies, tensile tests were used to characterize the DBTT of molybdenum. Fracture toughness tests provided more accurate measurements of the DBTT for potential applications due to the predominant triaxial stress state during the experiments ahead of the crack tip. ${ }^{21-23}$ However, as structural materials are exposed to impact loadings, the Charpy impact test seems to be an adequate technique to gain a better understanding of fracture at high deformation speeds and low test temperatures at multi-axial stress states. $^{24,25,27}$ This testing method is, besides hardness and tensile tests, a common method for technical investigations in industry due to its simplicity. Charpy impact tests are a straightforward method to reveal brittleness caused by an increase of deformation speed or a decrease of test temperature, as it preferentially occurs in bcc metals. In recent studies, the mechanical properties of pipeline steels and ultrafine-grained bcc steels have been, among other methods, characterized by Charpy impact tests. ${ }^{27,28}$

In this work, Charpy impact tests are combined with advanced characterization techniques to relate mechanical properties to the microstructure of technically pure molybdenum. Tensile tests and Charpy impact tests were conducted on samples of a technically processed molybdenum plate to investigate the role of delamination and crystallography on the DBTT in order to give an overview of the DBTTs in differently oriented specimens of a technically pure molybdenum plate in its stress-relieved and recrystallized state. Scanning electron microscopy (SEM) and electron backscatter diffraction (EBSD) have been used to examine fracture surfaces and delamination cracks in more detail. The deviations in the DBTTs for different orientations and states are discussed in terms of delamination related to the apparent texture and grain shape.

\section{MATERIALS AND METHODS}

An industrially processed 14.5 -mm-thick plate of technically pure molybdenum in the stress-relieved and recrystallized state was used for this investigation. The concentration of the main impurities in this plate are shown in Table I.

The molybdenum plate was produced by a typical powder-metallurgical production route by cold-isostatic pressing followed by a conventional sintering process. Subsequent hot-rolling was performed to reach a final thickness of $14.5 \mathrm{~mm}$.

Tensile tests at room temperature were carried out on round $5 \times 25 \mathrm{~mm}$ tensile test specimens, based on the DIN 50125, taken longitudinal (L) and transverse (T) to the rolling direction of the processed molybdenum plate in the stress-relieved and recrystallized state. After passing the yield point $\left(\mathrm{Rp}_{0.2}\right.$ or $\left.\mathrm{Re}\right)$ with $30 \mathrm{MPa} \mathrm{s}^{-1}$, a constant crosshead speed of $5 \mathrm{~mm} \mathrm{~min}^{-1}$ with a gauge length of $25 \mathrm{~mm}$ was used according to DIN EN ISO 6892-1-method B.

The samples used for the Charpy impact toughness tests were 2-mm-deep V-notched specimens with the dimensions $10 \mathrm{~mm} \times 10 \mathrm{~mm} \times 55 \mathrm{~mm}$, derived on the DIN EN ISO 148-1 standard. Figure 1 shows the extraction directions $(\mathrm{L}-\mathrm{S}, \mathrm{L}-\mathrm{T}, \mathrm{T}-$ $\mathrm{S}, \mathrm{T}-\mathrm{L})$ of the specimens relative to the plate processing geometry according to ASTM E399. The two-letter code was used to specify the samples, with the first letter indicating the normal direction to the crack plane and the second letter describing the direction of the global crack propagation.

After manufacturing the Charpy specimens, a stress-relief annealing treatment was performed. The recrystallization treatment was performed on the final V-notched samples. Ultrasonic tests were performed to exclude pre-damaged samples. The impact tests were conducted between room temperature and $500^{\circ} \mathrm{C}$ in a Zwick-Roell testing machine (BRA 342038204) with a RKP300 Joule and RKP450 Joule Charpy impact hammer. The specimens were heated in an HKE furnace and the temperature was measured by a thermocouple on the surface of the sample. When the set-point temperature was

Table I. Concentration of the main impurities in the investigated molybdenum plate

\begin{tabular}{lc}
\hline Element & Concentration $(\mu \mathbf{g} / \mathbf{g})$ \\
$\mathrm{C}$ & 19 \\
$\mathrm{O}$ & 11 \\
$\mathrm{Fe}$ & 6 \\
$\mathrm{~W}$ & 126 \\
\hline
\end{tabular}




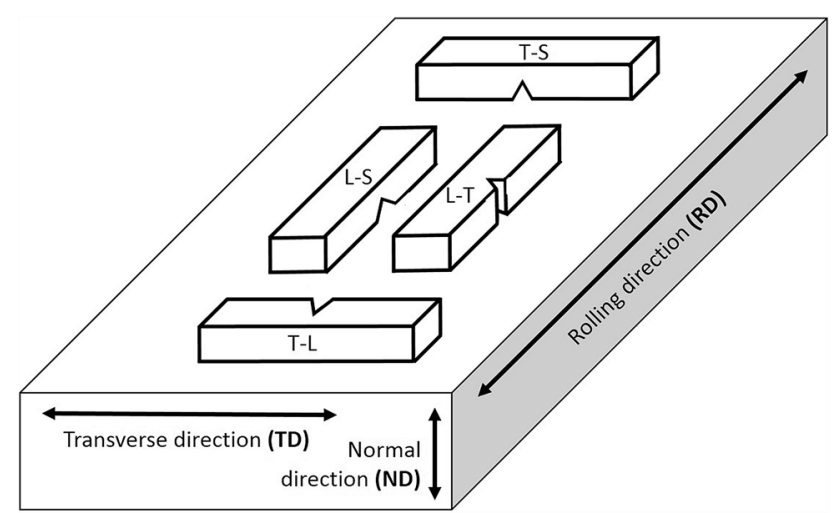

Fig. 1. The extraction direction of the specimens relative to the plate processing geometry ( $R D$ rolling direction, $N D$ normal direction, $T D$ transverse direction) is specified by the two-letter code according to ASTM E399. $L$ is the direction of principal deformation (maximum grain flow), $T$ represents the direction of least deformation, and $S$ the third orthogonal direction. The two-letter code was used to specify the samples with the first letter indicating the normal direction to the crack plane and the second letter describing the direction of the global crack propagation.

reached, the specimen was moved to the testing machine and analyzed after at least $2 \mathrm{~s}$. According to DIN EN ISO 148-1, a Charpy impact test is valid when the absorbed impact energy is lower than $80 \%$ of the potential starting energy and the crack propagated in the designated crack growth direction indicated by the V-notch.

The stress-relieved specimens were measured in the $\mathrm{L}-\mathrm{S}, \mathrm{L}-\mathrm{T}, \mathrm{T}-\mathrm{S}$, and $\mathrm{T}-\mathrm{L}$ orientations. The $\mathrm{L}-\mathrm{S}$ and T-S samples were tested with the $450 \mathrm{~J}$ hammer and the $\mathrm{L}-\mathrm{T}$ and $\mathrm{T}-\mathrm{L}$ samples with the $300 \mathrm{~J}$ hammer. Additionally, recrystallized specimens in the $\mathrm{L}-\mathrm{S}$ and $\mathrm{L}-\mathrm{T}$ directions were investigated. The DBTT was determined at the half-value of the upper shelf energy in the obtained Charpy curves. In all curves, the standard deviation is only shown if the value scatters more than $5 \mathrm{~J}$.

The samples for EBSD investigations were prepared by mechanically grinding and polishing followed by an electrolytic polishing with a 12.5 vol.\% $\mathrm{H}_{2} \mathrm{SO}_{4}$ solution. The EBSD scans were taken with $30 \mathrm{kV}, 2.5$ spot size, $8 \times 8$ binning and $10 \mathrm{~mm}$ working distance or with $6 \times 6$ binning and $15 \mathrm{~mm}$ working distance in a FEI Versa 3D DualBeam focused ion beam/scanning electron microscope (FIB/SEM) workstation equipped with an EDAX Hikari XP EBSD system. Inverse pole figure (IPF) maps were used to characterize the microstructural evolution and texture. The fracture surfaces close to the V-notch were analyzed in a stereomicroscope (Zeiss Discovery V20) and the SEM. The macro- and microscopic delamination was investigated by EBSD analyses. The Charpy specimens for EBSD analyses were prepared before the impact tests to prevent artifacts due to the grinding and polishing process.

\section{RESULTS}

\section{Microstructure and Tensile Test}

In Fig. 2, the microstructures of molybdenum in the stress-relieved (a) and recrystallized (b) state are shown. A distinct recovered sub-grain structure with a weak rotated cube texture is present in the warm-deformed and stress-relieved state. Recrystallization leads to an almost globular grain shape with a mean grain size of $92 \mu \mathrm{m}$ and a random texture with a small maximum at the weak $\gamma$-fiber showing a $<111>$ direction parallel to the normal direction (ND).

Tensile tests indicate differences in strength and elongation depending on the specimen orientation in the plate and the applied heat treatment. Stressrelieved molybdenum shows a higher yield $(617 \mathrm{MPa}$ and $688 \mathrm{MPa})$ and tensile strength (665 MPa and $685 \mathrm{MPa}$ ) as well as a larger fracture strain $(32.5 \%$ and $22.2 \%)$ and uniform elongation (7.7\% and 6\%) compared to recrystallized molybdenum. For all longitudinal samples, a slight increase in the uniform elongation was measured. Specimens tested in the transversal direction exhibit a less ductile behavior and an increase of strength. The results of all tensile tests are shown in the electronic supplementary Table I.

\section{Charpy Impact Tests of Stress-Relieved Molybdenum}

In Fig. 3a, data of the impact tests on differently oriented stress-relieved molybdenum samples are presented. For L-T and T-L oriented samples, a low upper shelf energy of around $53 \mathrm{~J}$ was found, whereas the upper shelf energy of $\mathrm{L}-\mathrm{S}$ and $\mathrm{T}-\mathrm{S}$ is significantly higher with energy values of around $300 \mathrm{~J}$ for the $\mathrm{L}-\mathrm{S}$ and $150 \mathrm{~J}$ for the T-S orientation. The transition from brittle to ductile behavior occurs for $\mathrm{L}-\mathrm{S}$ and $\mathrm{L}-\mathrm{T}$ samples in a similar temperature range of around $100-250^{\circ} \mathrm{C}$ and for $\mathrm{T}-\mathrm{L}$ and T-S of around $200-350^{\circ} \mathrm{C}$. The T-L and L$\mathrm{T}$ oriented specimens exhibit a typical DBTT-curve with no significant scattering. The upper shelf energy is around $53 \mathrm{~J}$ but a slight shift to higher energy values and a lower DBTT (shown in Fig. 3b) is visible for the $\mathrm{L}-\mathrm{T}$ orientation. The energy values of $\mathrm{L}-\mathrm{S}$ and T-S show more scattering in comparison to the $\mathrm{L}-\mathrm{T}$ and $\mathrm{T}-\mathrm{L}$ orientations.

\section{$T-L$ and $L-T$ Orientation}

The fracture surfaces close to the notch root of the $\mathrm{L}-\mathrm{T}$ and $\mathrm{T}-\mathrm{L}$ specimens at $23^{\circ} \mathrm{C}$ (lower shelf), $150^{\circ} \mathrm{C}$ (transition), and $300^{\circ} \mathrm{C}$ (upper shelf) are shown in the electronic supplementary Fig. 1. At room temperature, i.e. in the lower shelf region, both orientations exhibit transgranular cleavage (electronic supplementary Fig. 1a and d). At $150^{\circ} \mathrm{C}$, the L-T oriented sample indicates the transition to a ductile fracture behavior with dimples visible on the fracture surface. At the same temperature, the T-L 
(a)

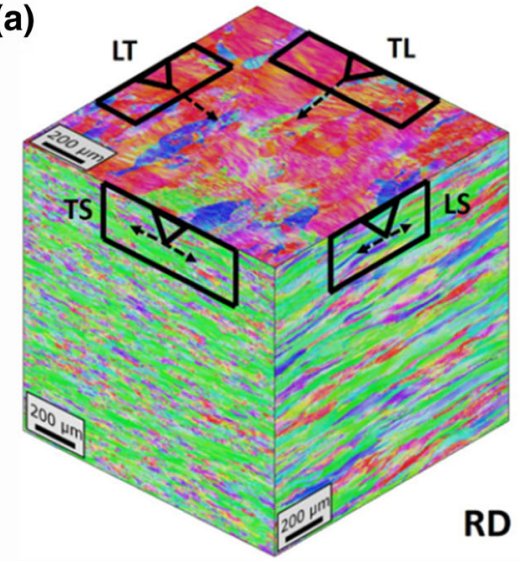

(b)

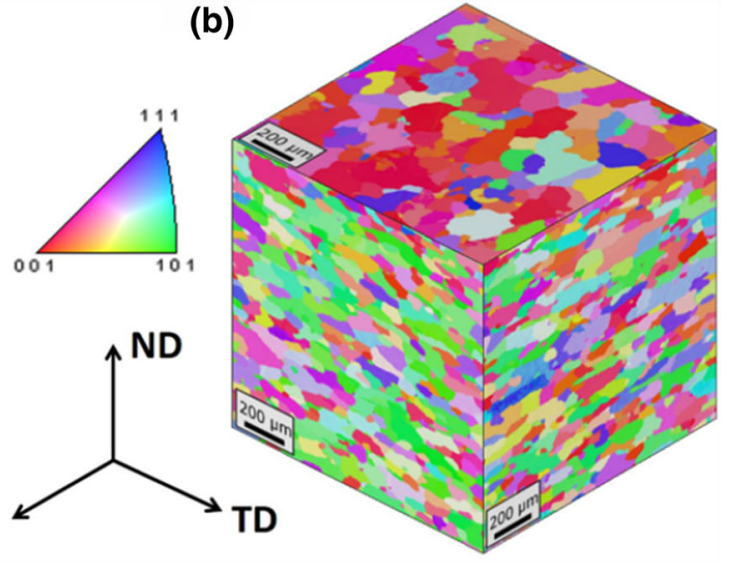

Fig. 2. IPF maps of molybdenum in the (a) stress-relieved and (b) recrystallized state determined by EBSD. The insets in the middle show the IPF coloring, which indicates the crystal direction perpendicular to the specimen surface, and the orientation of the cube in respect to the rolling process. In (a) the orientation of the tested samples are marked.

oriented sample still breaks almost in the brittle fracture mode. The same trend is visible in the DBTT-curves in Fig. 3 with a higher energy value for the $\mathrm{L}-\mathrm{T}$ direction than for the T-L at $150^{\circ} \mathrm{C}$. At $300^{\circ} \mathrm{C}$, both sample orientations show a ductile fracture behavior, prominent for the upper shelf. In the transition region, microscopic delamination cracks normal to the global crack propagation direction start to appear. In Fig. $4 \mathrm{a}$ and b. stereographic images of the fracture surfaces of samples in the $\mathrm{L}-\mathrm{T}$ and $\mathrm{T}-\mathrm{L}$ orientations tested in the transition region $\left(225^{\circ} \mathrm{C}\right)$ are presented. At this temperature, ductile laminate features (white arrows in Fig. 4a and b) start to occur. In L-T oriented samples, more delamination cracks can be seen than in T-L oriented samples. This is even more evident by analyzing the SEM images of both orientations tested at $400^{\circ} \mathrm{C}$ in the upper shelf, which are shown in Fig. $4 c$ and d. The L-T orientation exhibits finer ductile sheet-like laminate features than the T-L orientation.

The microscopic delamination cracks in $\mathrm{L}-\mathrm{T}$ and $\mathrm{T}-\mathrm{L}$ orientation occur normal to the global crack growth direction. An EBSD investigation of a longer delamination crack shown in Fig. 5a indicates that cracks propagate between grains with high misorientation (see IPF maps in Fig. 5b and c). It seems obvious that delamination occur along high-angle grain boundaries (HAGB).

\section{$T-S$ and $L-S$ Orientation}

Figure 6a represents a $\mathrm{L}-\mathrm{S}$ specimen tested in the lower shelf region $\left(50^{\circ} \mathrm{C}\right)$ with macroscopic delamination cracks. These delamination cracks do not propagate in the designated crack growth direction, but branch parallel to the longitudinal direction of the impact test bars. With a closer investigation of the surface of the delamination (marked by the arrow in Fig. 6a), a typical intergranular fracture surface can be observed in Fig. $6 \mathrm{~b}-\mathrm{d}$. The L-S oriented samples did not break into two pieces above $150^{\circ} \mathrm{C}$ and the T-S oriented samples not above $250^{\circ} \mathrm{C}$.

In the transition region, the $\mathrm{T}-\mathrm{S}$ oriented specimens also exhibits delamination cracks and large deviations from the global crack path. The variation in the position and the size of delamination cracks results in a strong scattering of the energy values in the DBTT-curve, as visible in Fig. 3a. In the electronic supplementary Fig. 2a, a T-S sample tested at $50^{\circ} \mathrm{C}$ is presented. The arrows mark large delamination cracks.

To study these cracks in more detail, EBSD investigations were performed. In the electronic supplementary Fig. 2b-d delamination cracks are shown in SEM images and IPF maps. Typically, delamination takes place between different grain orientations, as visible in the electronic supplementary Fig. 2b. This behavior is shown in more detail in high-magnification EBSD analyses in the electronic supplementary Fig. 2c and d. These cracks propagate between grains of high misorientation; however, cracks also occur perpendicular to the delamination in regions with small grain misorientation (white arrow).

\section{Charpy Impact Tests of Recrystallized Molybdenum}

After recrystallization, the molybdenum samples exhibit an almost globular grain structure as shown in Fig. 2b. In the DBTT-curves of recrystallized molybdenum in the $\mathrm{L}-\mathrm{T}$ and $\mathrm{L}-\mathrm{S}$ orientations, shown in Fig. 7a, a clear increase of the DBTT is apparent in comparison to stress-relieved molybdenum. The $\mathrm{L}-\mathrm{T}$ oriented samples of the recrystallized state show higher upper shelf energy than in the stress-relieved state. For the L-S orientation, an upper shelf energy of around $300 \mathrm{~J}$ for both stress-relieved and recrystallized molybdenum can be observed. Both orientations in the 

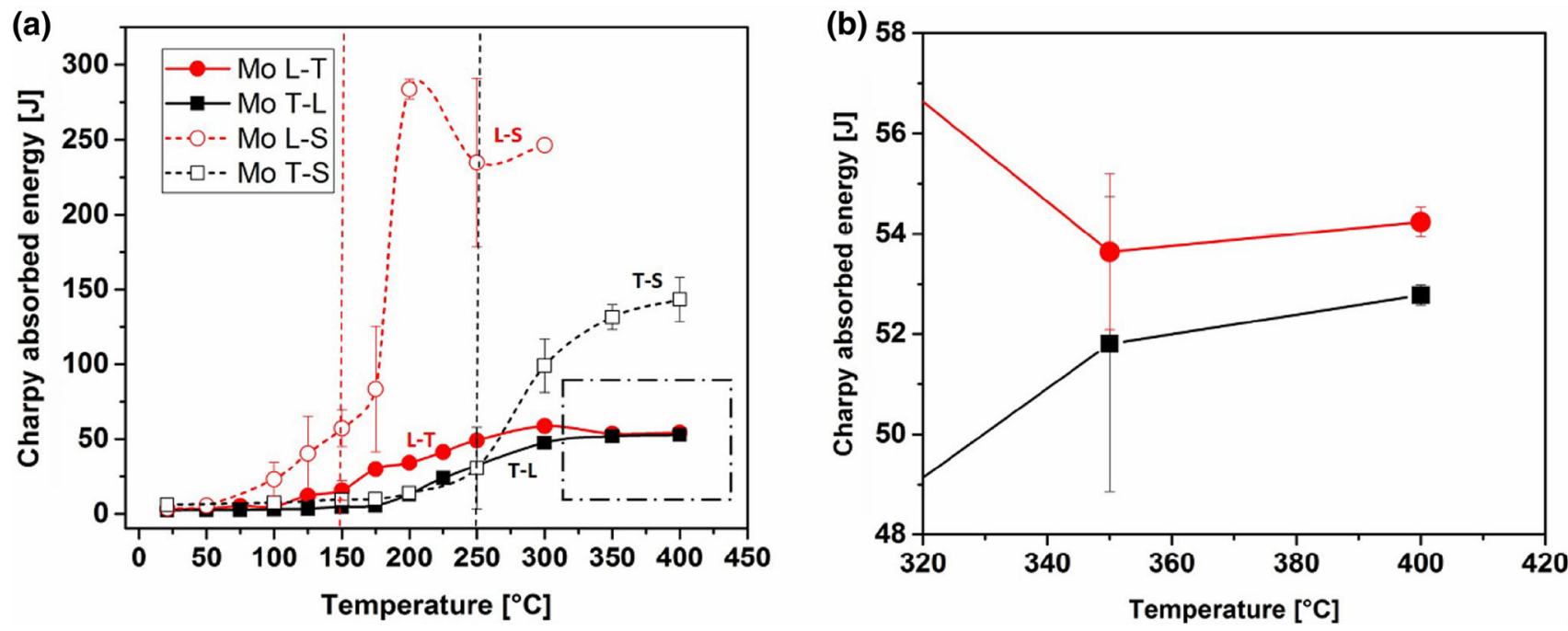

Fig. 3. (a) Charpy impact test curves for molybdenum in the stress-relieved state in all four orientations. The vertical dashed lines indicated the temperatures above which the samples did not break anymore during the impact test (red for L-S orientation, black for T-S orientation). (b) Data of the upper shelf region of T-L and L-T, marked by the inset in (a), between 320 and $420^{\circ} \mathrm{C}$. Note: In (a) the standard deviation is only shown if values scatter more than $5 \mathrm{~J}$. Only in (b) the scattering for values lower than $5 \mathrm{~J}$, is presented.
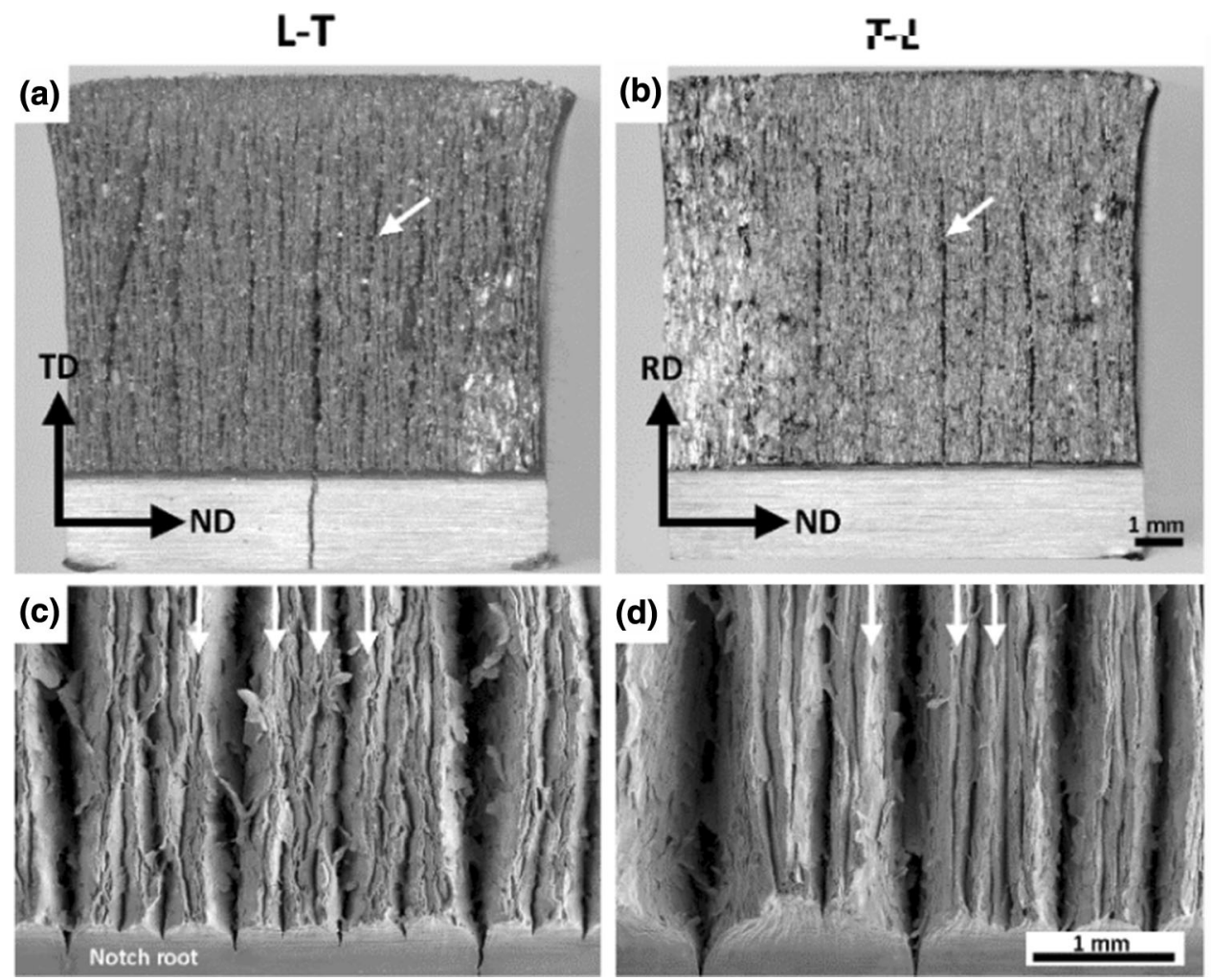

Fig. 4. Analyses of the fracture surfaces in the transition region $\left(225^{\circ} \mathrm{C}\right)$ and upper shelf region $\left(400^{\circ} \mathrm{C}\right)$. (a) Stereomicroscope image of the $\mathrm{L}-\mathrm{T}$ orientation tested at $225^{\circ} \mathrm{C}$. (b) Stereomicroscope image of the T-L orientation tested at $225^{\circ} \mathrm{C}$. (c) SEM image close to the former V-notch of the $\mathrm{L}-\mathrm{T}$ orientation tested at $400^{\circ} \mathrm{C}$. (d) SEM image close to the former V-notch of the T-L orientation tested at $400^{\circ} \mathrm{C}$.

recrystallized condition indicate a similar DBTT lying between 400 and $450^{\circ} \mathrm{C}$. The image visible in Fig. $7 \mathrm{~b}$ represents a characteristic specimen tested at $450^{\circ} \mathrm{C}$ in the upper shelf region. Due to the ductile behavior at elevated temperatures, the samples did not break. No large delamination cracks can be observed in both tested orientations. The DBTT of the $\mathrm{L}-\mathrm{T}$ orientation is slightly shifted to lower values. 

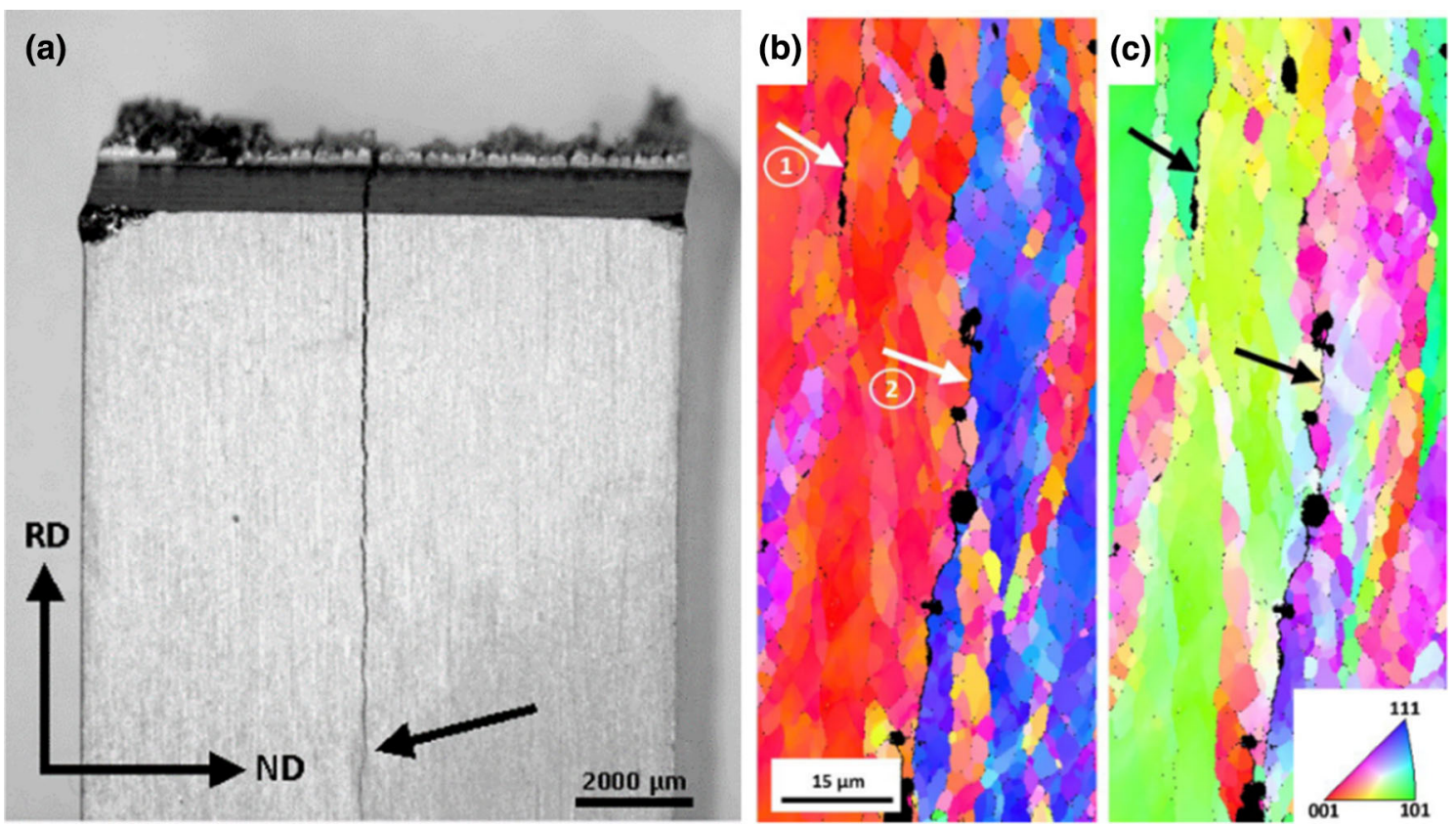

Fig. 5. (a) Stereomicroscope image of the half impact bar (side view) tested in L-T orientation in the transition region (150 $\left.{ }^{\circ} \mathrm{C}\right)$. (b) IPF map of delamination cracks marked in Fig. 6a. Two cracks are visible. (c) 90 degree rotated IPF map. The inset in the lower right corner shows the IPF coloring which indicates the crystal direction perpendicular to the (b) ND and (c) TD direction.
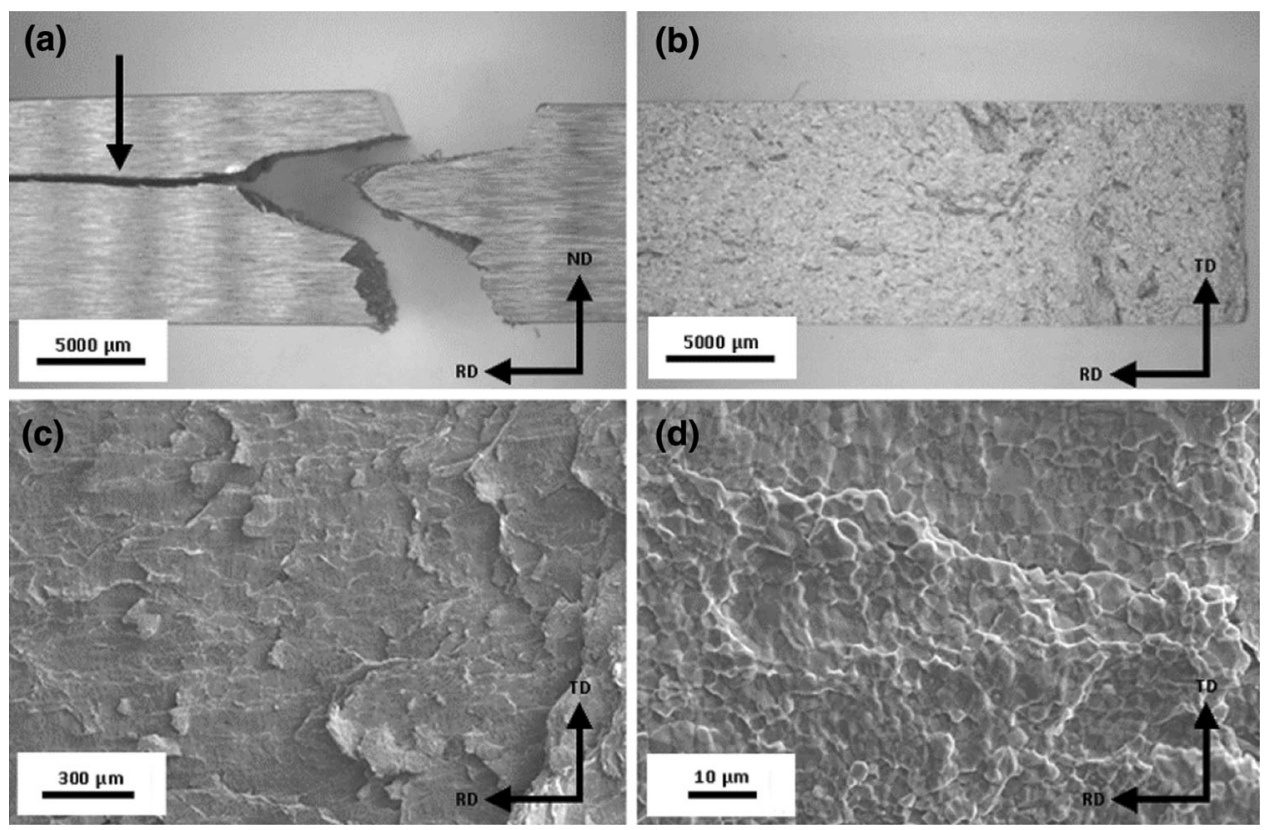

Fig. 6. (a) Stereomicroscope image of a L-S specimen tested in the lower shelf region $\left(50^{\circ} \mathrm{C}\right.$ ) with macroscopic delamination cracks. (b) Stereomicroscope image of the delamination marked by the arrow in (a). (c) SEM image of the delamination shown in (b). (d) Higher magnification SEM image of the delamination visible in (c).

In the electronic supplementary Fig. 3a-c, the fracture surfaces of the $\mathrm{L}-\mathrm{T}$ and $\mathrm{L}-\mathrm{S}$ oriented samples in the recrystallized state in the lower shelf are shown (sample tested at $23^{\circ} \mathrm{C}$ and $375^{\circ} \mathrm{C}$ for the $\mathrm{L}-\mathrm{T}$ orientation and $250^{\circ} \mathrm{C}$ for the $\mathrm{L}-\mathrm{S}$ orientation). Intergranular fracture behavior with small transgranular cleavage regions can be observed in both orientations in the lower shelf region. However, in the transition and upper shelf regions, the $\mathrm{L}-\mathrm{T}$ specimens exhibit a small tendency towards delamination. In the electronic supplementary Fig. 3d, the SEM image of the fracture surface of a $\mathrm{L}-\mathrm{T}$ oriented sample tested in the transition region $\left(375^{\circ} \mathrm{C}\right)$ is presented, where small 


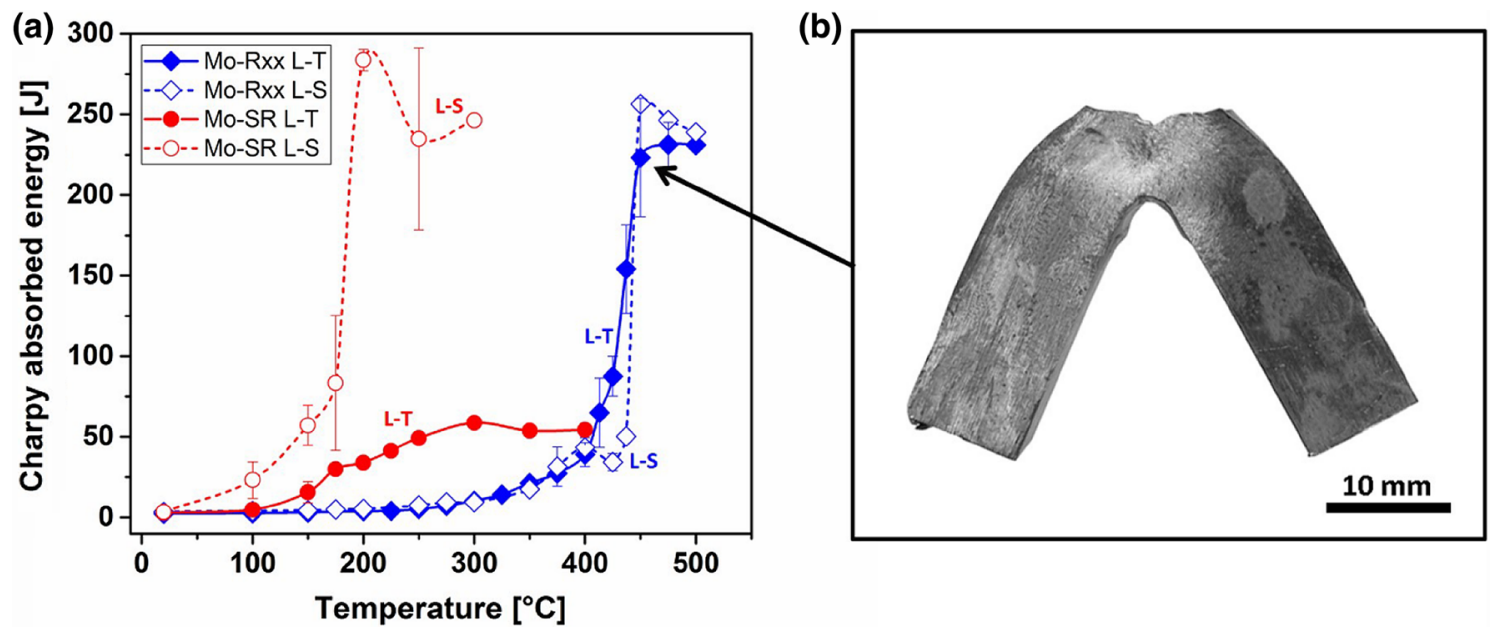

Fig. 7. (a) Charpy impact test curves of recrystallized molybdenum in the L-T and L-S orientation. (b) Photograph of a tested L-T sample at $450^{\circ} \mathrm{C}$.

delamination cracks can be observed (marked with an arrow). The L-S oriented samples show no delamination in the transition- and upper shelf region.

\section{Ductile-to-Brittle Transition Temperatures}

To compare the obtained results, all DBTTs are summarized in Table II. In the stress-relieved state, the lowest DBTT with $169^{\circ} \mathrm{C}$ was determined for the $\mathrm{L}-\mathrm{T}$ orientation. The $\mathrm{L}-\mathrm{S}$ oriented specimens show a slightly higher DBTT $\left(181^{\circ} \mathrm{C}\right)$, followed by the T-L oriented samples with $229^{\circ} \mathrm{C}$. T-S oriented samples indicate the highest DBTT with $280^{\circ} \mathrm{C}$. After recrystallization, the DBTT increased significantly. Both orientations, $\mathrm{L}-\mathrm{T}$ and $\mathrm{L}-\mathrm{S}$, exhibit equal transition values of around $429-442^{\circ} \mathrm{C}$. Only a small difference can be observed.

\section{DISCUSSION}

In the following, the results from tensile tests at room temperatures and Charpy impact experiments between $23^{\circ} \mathrm{C}$ and $500^{\circ} \mathrm{C}$ are discussed, with special focus on the orientation dependency and micro-and macroscopic delamination in technically pure molybdenum.

\section{Tensile Tests}

The tensile tests exhibit the typical decrease in yield and tensile strength due to recrystallization of molybdenum. The embrittlement is deduced by the uniform elongation, which is reduced from 6\%-8\% to $2 \%-3 \%$. By a closer examination of the stressrelieved condition of the transversal sample (T), a slight increase of yield and tensile strength as well as a drop of fracture strain and uniform elongation can be observed. The same tendencies were found for stress-relieved molybdenum ${ }^{4}$ and for an API-X80 pipeline steel, ${ }^{27}$ which was explained by a closer spacing of grain boundaries in the transversal orientation.

\section{Stress-Relieved Molybdenum in the Charpy Impact Test}

In general, the stress-relieved samples can be classified in two groups. Firstly, there are the L-T and T-L oriented samples, where the global crack propagates in the designated crack growth direction. Secondly, in the L-S and T-S oriented samples, the crack deviates from the designated direction due to macroscopic delamination. Due to the additional delamination cracks, the local driving force for the crack propagation is reduced for $\mathrm{L}-\mathrm{S}$ and $\mathrm{T}-\mathrm{S}$ and a larger surface area is created, leading to higher upper shelf energies. However, it seems that the DBTT values are more influenced by the orientation of the crack plane than by the crack propagation direction for $\mathrm{L}-\mathrm{T}$ and $\mathrm{L}-\mathrm{S}$. The $\mathrm{T}-\mathrm{L}$ and T-S show similar transition regions. In the following, the characteristics of the two groups will be discussed in more detail.

\section{$T-L$ and $L-T$ Orientation}

L-T and T-L samples show quite similar DBTT curves, with a slightly higher upper shelf energy and a lower DBTT for L-T. Both orientations have in common that cracks propagate without large deviations in the designated crack growth direction.

The DBTTs are in good accordance with the fracture surface observations indicating the transition from a transgranular cleavage to a ductile laminate failure mode with dimples. In these orientations, the designated crack growth direction is parallel to the long axis of the elongated grains. Thus, the crack can easily propagate along the HAGBs. However, microscopic delamination was 


\begin{tabular}{|c|c|c|c|c|}
\hline & \multicolumn{4}{|c|}{ DBTT $\left({ }^{\circ} \mathrm{C}\right)$} \\
\hline & L-T & T-L & L-S & $\mathbf{T}-\mathbf{S}$ \\
\hline $\begin{array}{l}\text { Mo stress-relieved } \\
\text { Mo recrystallized }\end{array}$ & $\begin{array}{l}169 \\
429\end{array}$ & 229 & $\begin{array}{l}181 \\
442\end{array}$ & 280 \\
\hline
\end{tabular}

found on both fracture surfaces perpendicular to the crack growth direction in the transition and upper shelf region. It is well known that the occurrence of these delamination cracks, which look like thin sheet ligaments, generate a toughening mechanism, also known as delamination toughening. ${ }^{4,20,24,27,28}$ These thin ligaments deform plastically under a plane stress state introducing a larger plastic zone. The fracture toughness is increased due to the relaxation of the triaxial stress state at the crack tip. By the formation of microscopic delamination cracks, the thickness of the original sample is reduced to a bunch of many small thin sheet ligaments. The triaxial stress component decreases causing a plane stress state. The sample acts like a stack of many thin samples instead of one thick sample. Thinner delamination segments will have a larger tendency for plane stress with the result of a higher toughness. ${ }^{27}$ Delamination toughening can be observed, for example, in the $\mathrm{L}-\mathrm{T}$ oriented samples in Fig. 4. Comparing the fracture surfaces of the $\mathrm{T}-\mathrm{L}$ and $\mathrm{L}-\mathrm{T}$ orientations, the $\mathrm{L}-\mathrm{T}$ samples exhibit thinner ligaments which lead to an improved toughness in the upper shelf energy apparent in the DBTT-curves, shown in Fig. 3b. Hence, an increase of around $2 \mathrm{~J}$ of the upper shelf energy for the $\mathrm{L}-\mathrm{T}$ orientation can be observed. The same toughening effects were studied by Joo et al. ${ }^{24,28,29}$ in an API-X80 steel, by Song et al. ${ }^{27,30}$ and by Kimura et al. ${ }^{26}$ in an ultrafine grained steel, by Hohenwarter ${ }^{31}$ in an ultrafine-grained fully perlitic steel, and by Cockeram ${ }^{20,22}$ in wrought molybdenum and its alloys. EBSD investigations of such delamination cracks (Fig. 5) indicate cracking along HAGB which correlates well with the result of Cockeram, ${ }^{20,22}$ who describes delamination as the splitting of grain boundaries. In recent atom probe studies, oxygen, phosphorus and nitrogen segregations at HAGB were found, which can decrease the grain boundary strength causing these grain boundary cracks. ${ }^{15}$ Additionally, it is believed that the HAGBs of molybdenum are intrinsically weak. $^{7,8,32}$

The DBTT of the $\mathrm{L}-\mathrm{T}$ oriented sample is lower, which can be correlated with the premature occurrence of delamination cracks causing an increase in toughness. This phenomenon seems to be mainly influenced by the orientation of the crack plane independent of the crack propagation direction.

\section{$T-S$ and $L-S$ Orientation}

Both orientations exhibit a higher upper shelf energy than the T-L and L-T orientations which is related to large deviations in the crack path, caused by macroscopic delamination. The cracks branch perpendicular to the designated propagation direction, whereby the local crack driving force is reduced and, even more, a much larger new surface is created. As a consequence, the upper shelf energy is significantly higher than in the $\mathrm{T}-\mathrm{L}$ and $\mathrm{L}-\mathrm{T}$ orientations and depends on the degree of macroscopic delamination. ${ }^{26}$ Each sample showed delamination of a different extent, which explains the intense scattering of the energy values especially in L-S oriented samples. The vertical dashed lines in the DBTT-curves in Fig. 3 indicate the temperature at which the specimens did not break into two pieces due to pronounced delamination. In the $\mathrm{L}-\mathrm{S}$ samples, the designated crack plane is perpendicular to the longer axis of the elongated grains, causing the strongest delamination effect (visible in Fig. 6). In the T-S oriented specimens, the grain elongation is less pronounced (visible in Fig. 2a), leading to less pronounced delamination (electronic supplementary Fig. 2a). The occurrence of delamination in the Charpy impact test is related to weak interfaces or planes normal to the $\mathrm{V}$-notch and the designated crack growth direction of the samples. ${ }^{26}$ EBSD investigations of the T-S oriented samples (visible in the electronic supplementary Fig. $2 b-d$ ) reveal a splitting of grain boundaries between grains with high misorientation. High-magnification SEM images indicate that the crack tips grow along HAGB, especially between the strong partial $\alpha$-fiber with $<110>/ / \mathrm{RD}$ and the weak $\gamma$-fiber with $<111>/ /$ ND. ${ }^{33,34}$ Kimura et al. ${ }^{26}$ identified the anisotropic grain shape as the main reason for the occurrence of delamination. Strength, toughness and ductility are significantly increased at low temperatures due to ultrafine elongated grains along the rolling direction and nanometer particles which promote splitting between the grain boundaries. In this study, the molybdenum plate shows a weak texture, but the crack follows the interfaces between the slight $\gamma$ and $\alpha$-fibers along HAGBs. Between these boundaries, a transgranular fracture is also observed, where the crack connects elongated grain boundaries, as visible in the electronic supplementary Fig. 2b (marked by an arrow). By a closer 
investigation of the fracture surface of the delamination (visible in Fig. 6b-d), a typical intergranular fracture mode is apparent. It is interesting that delamination, which is a result of brittle fracture, causes an increase in Charpy impact toughness. Therefore, the L-S oriented samples in the stressrelieved state seem to be the toughest orientation due to enhanced macroscopic delamination.

\section{Recrystallized Molybdenum in the Charpy Impact Test}

In order to study the effect of texture and grain elongation on the DBTT and the delamination behavior, the recrystallized condition of the molybdenum plate in the $\mathrm{L}-\mathrm{T}$ (microscopic delamination in the stress-relieved state) and L-S orientations (macroscopic delamination in the stress-relieved state) has been studied.

After recrystallization, an almost globular grain structure with a weak $\gamma$-fiber can be observed. However, the grains are still slightly elongated along the rolling direction, as visible in Fig. 2b.

The DBTT-curves of the recrystallized molybdenum reveal a clear increase in the DBTT compared to the stress-relieved condition. In the lower shelf, intergranular facture is apparent for both orientations (visible in the electronic supplementary Fig. 3a-c). On the one hand, this embrittlement is a result of impurities, which segregate to the grain boundaries. Especially, oxygen segregation weakens the grain boundaries. ${ }^{6,11,12}$ On the other hand, it is believed that the embrittlement is an intrinsic property of molybdenum. ${ }^{7,8,32}$ Intergranular fractures occur more often in microstructures with many random high-angle grain boundaries. Lowangle and special boundaries, such as sigma grain boundaries, seem to cause transgranular fractures. ${ }^{8}$

In addition, the shape of the grains influences the DBTT. The slight elongation of the grains causes no branching of the crack and, therefore, no delamination occurs which leads to an increase in the DBTT. ${ }^{25}$

In the transition region of the $\mathrm{L}-\mathrm{T}$ samples, small ductile laminate features can be observed which are similar to the ligaments in the $\mathrm{L}-\mathrm{T}$ samples in the stress-relieved state. A small decrease in the DBTT for the $\mathrm{L}-\mathrm{T}$ sample is apparent compared to $\mathrm{L}-\mathrm{S}$ (L$\mathrm{T}$ at $429^{\circ} \mathrm{C}, \mathrm{L}-\mathrm{S}$ at $442^{\circ} \mathrm{C}$ ), which can be related to this delamination toughing effect.

\section{CONCLUSION}

In this study, advanced characterization techniques were successfully combined with simple Charpy impact tests to relate the mechanical properties to the microstructure of technically pure molybdenum, especially regarding its toughness and delamination behavior. An anisotropy of fracture toughness in stress-relieved molybdenum was observed due to a pancake-shaped, elongated grain structure. Hence, the grain geometry controls the crack propagations. Elongated grains led to enhanced delamination in Charpy impact test depending on the specimen orientation. Microscopic delamination in the $\mathrm{L}-\mathrm{T}$ and $\mathrm{T}-\mathrm{L}$ samples in the stress-relieved state were found to be beneficial due to the effect of delamination toughening. A pronounced increase of toughness is apparent in the $\mathrm{L}-\mathrm{S}$ and T-S samples, which is related to macroscopic delamination. These delamination cracks follow grain boundaries between grains of high misorientation, which are weakened by impurities at the interfaces. Although delamination is a result of brittle fracture, an increase in toughness in the Charpy impact test is provoked. Therefore, the $\mathrm{L}-\mathrm{S}$ oriented samples reveal the highest toughness, followed by the T-S and L-T samples. The T-L oriented samples showed the lowest resistance against crack propagation. Recrystallization leads to a significant increase of the DBTT, caused by the globular grain structure and impurities present at the grain boundaries. In conclusion, the elongated grain structure plays a significant role for the toughness of bccstructured metals, especially in correlation with the weak bonding of random high-angle grain boundaries in molybdenum, which are related to either an extrinsic (grain boundary segregation) or an intrinsic (microstructure) property.

\section{ACKNOWLEDGEMENT}

Open access funding provided by Montanuniversität Leoben. Thanks to Walter Kopper, the responsible technician of the Charpy impact test machine at our Department, who conducted all impact tests for this study. Furthermore, the authors are grateful to Dipl.-Ing. Thomas Leitner from the Chair of Materials Physics of the Montanuniversität Leoben for his scientific and technical input in terms of fracture mechanics.

\section{OPEN ACCESS}

This article is distributed under the terms of the Creative Commons Attribution 4.0 International License (http://creativecommons.org/licenses/by/4.0/), which permits unrestricted use, distribution, and reproduction in any medium, provided you give appropriate credit to the original author(s) and the source, provide a link to the Creative Commons license, and indicate if changes were made.

\section{ELECTRONIC SUPPLEMENTARY MATERIAL}

The online version of this article (doi:10.1007/ s11837-016-2075-y) contains supplementary material, which is available to authorized users.

\section{REFERENCES}

1. W. Martienssen and H. Warlimont: Springer Handb. Condens. Matter Mater. Data (Berlin, Heidelberg, New York: Springer, 2005), pp. 304-318. 
2. T. Watanabe and S. Tsurekawa, J. Mater. Sci. Eng. A 387389, 447 (2004).

3. L. Northcott, Metallurgy of the Rarer Metals - 5 (Molybdenum (London: Butterworths Scientific Publications, 1956), p. 222.

4. B.V. Cockeram, E.K. Ohriner, T.S. Byun, M.K. Miller, and L.L. Snead, J. Nucl. Mater. 382, 229 (2008).

5. H. Kimura, Trans. Jpn. Inst. Met. 29, 521 (1988).

6. A. Kumar and B.L. Eyre, Proc. R. Soc. A 370, 431 (1980).

7. J.B. Brosse, R. Fillet, and M. Biscondi, Scr. Metall. 15, 619 (1981).

8. S. Tsurekawa, T. Tanaka, and H. Yoshinaga, J. Mater. Sci. Eng. A 176, 341 (1994).

9. A. Tahir, R. Janisch, and A. Hartmaier, Modell. Simul. Mater. Sci. Eng. 21, 075005 (2013).

10. E. Pink and R. Eck, in Mater. Sci. Technol., ed. R. W. Cahn, P. Haasen, E. J. Kramer, and K. H. Matucha (Weinheim, New York, Basel, Cambridge, Tokyo: VCH, 2006), pp. 591638.

11. M.K. Miller and A.J. Bryhan, J. Mater. Sci. Eng. A 327, 80 (2002).

12. A.S. Drachinskiy, A.V. Kraynikov, and V.N. Slyunyayev, Phys. Met. Metallogr. 66, 111 (1988).

13. A. Krajnikov, A. Drachinskiy, and V. Slyunyaev, Int. J. Refract. Met. Hard Mater. 11, 175 (1992).

14. K. Babinsky, J. Weidow, W. Knabl, A. Lorich, H. Leitner, and S. Primig, Mater. Charact. 87, 95 (2014).

15. K. Babinsky, W. Knabl, A. Lorich, R. De Kloe, H. Clemens, and S. Primig, Ultramicroscopy 159, 445 (2015).

16. T. Kadokura, Y. Hiraoka, Y. Yamamoto, and K. Okamoto, Mater. Trans. 51, 1296 (2010).
17. C. Stickler: Plansee Report 97DEL2a 6 (1997).

18. R. Stickler and H. Hödl: Plansee Report 96DEL2a 12 (1996).

19. R. Stickler and H. Hödl: Plansee Report 96DEL3a 4 (1996).

20. B.V. Cockeram, J. Mater. Sci. Eng. A 528, 288 (2010).

21. B.V. Cockeram, Metall. Mater. Trans. A 36, 1777 (2005).

22. B.V. Cockeram, J. Mater. Sci. Eng. A 418, 120 (2006).

23. B.V. Cockeram, Metall. Mater. Trans. A 33, 3685 (2002).

24. M.S. Joo, D.-W. Suh, J.H. Bae, and H.K.D.H. Bhadeshia, J. Mater. Sci. Eng. A 546, 314 (2012).

25. Y. Hiraoka, H. Kurishita, M. Narui, and H. Kayano, Mater. Trans., JIM 36, 504 (1995).

26. Y. Kimura, T. Inoue, F. Yin, and K. Tsuzaki, Science 320, 1057 (2008).

27. R. Song, D. Ponge, and D. Raabe, Acta Mater. 53, 4881 (2005).

28. M.S. Joo, D.W. Suh, J.H. Bae, N.S. Mouriño, R. Petrov, L.A.I. Kestens, and H.K.D.H. Bhadeshia, J. Mater. Sci. Eng. A 556, 601 (2012).

29. M.S. Joo, D. Suh, J. Bae, and H.K.D.H. Bhadeshia, Mater. Sci. Technol. 30, 439 (2014).

30. R. Song, D. Ponge, D. Raabe, J.G. Speer, and D.K. Matlock, J. Mater. Sci. Eng. A 441, 1 (2006).

31. A. Hohenwarter, A. Taylor, R. Stock, and R. Pippan, Metall. Mater. Trans. A 42A, 1609 (2011).

32. T. Watanabe and S. Tsurekawa, Acta Mater. 47, 4171 (1999).

33. S. Primig, H. Leitner, and W. Knabl, Metall. Mater. Trans. A 43, 4794 (2012).

34. S. Primig, H. Leitner, W. Knabl, A. Lorich, H. Clemens, and R. Stickler, J. Mater. Sci. Eng. A 535, 316 (2012). 